\title{
An unusual case of prosthetic joint infection due to Arcanobacterium bernardiae
}

A 78-year-old man was admitted to the orthopaedic ward of the Centre Hospitalier Régional Universitaire for a haematoma of the left thigh which had appeared after a fall and 3 weeks of insidious pain. Medical history included a left total hip prosthesis because of a work accident 27 years previously. Examination revealed that his left hip prosthesis had worked loose, which was probably responsible for the fall. Laboratory data included a blood leukocyte count of $9.3 \times 10^{9} 1^{-1}$, with $73 \%$ polymorphonuclear leukocytes, and a Creactive protein level of $18 \mathrm{mg} \mathrm{l}^{-1}$. The haematoma was drained surgically and the prosthesis was removed and replaced by a spacer. During the intervention, four biopsies (haematoma, muscle, femur and acetabulum) were performed. Gram stain of the haematoma and the femur biopsy smears showed Gram-positive bacilli. As the patient was apyretic, blood cultures were not performed. A combination of linezolid and cefotaxime was started until the microbiological results were available.

The four biopsies grew only a Grampositive coryneform rod after $48 \mathrm{~h}$ incubation at $37{ }^{\circ} \mathrm{C}$. The presence of this bacterium in all per-operative samples led us to consider this bacterium as the origin of the total hip prosthesis infection and its loosening, as Atkins et al. (1998) showed that the isolation of an indistinguishable micro-organism from three or more independent specimens was highly predictive of infection. The unpigmented colonies were able to grow as well in an aerobic atmosphere as in an aerobic atmosphere. The strain grew better on Columbia agar in the presence of $5 \% \mathrm{CO}_{2}$. The isolate was catalase- and cytochrome oxidase-negative. The API CORYNE strip (bioMérieux) gave a final profile number 2010222 with a good identification for Arcanobacterium bernardiae (probability: $98.8 \%$; typicity: 0.94 ). To confirm the identification of this agent, which is rarely isolated in clinical samples, sequencing of the $16 \mathrm{~S}$ rRNA gene was performed using a
MicroSeq 500 16S rRNA Bacterial Sequencing kit (Applied Biosystems). The 407 bp fragment obtained was compared with NCBI GenBank entries by using the BLAST algorithm (http://

www.ncbi.nlm.nih.gov/BLAST). It showed $99 \%$ identity with the $16 \mathrm{~S}$ rRNA gene of Arcanobacterium bernardiae strain DSM $9152^{\mathrm{T}}$ (GenBank accession no. X79224) previously determined by Funke et al. (1995). In vitro susceptibility tests were performed using the diffusion method by Etest (AES) on Mueller-Hinton medium with $5 \%$ sheep blood. As no specific recommendations exist for this bacterium, the breakpoints described for general bacteria by CA-SFM 2008 (Comité de l'Antibiogramme de la Société Française de Microbiologie; http://www.sfm.asso.fr) allowed us to consider that this bacterium was only resistant to penicillin $\mathrm{G}$ $\left(\mathrm{MIC}=0.5 \mathrm{mg} \mathrm{l}^{-1}\right)$, amikacin $\left(\mathrm{MIC}=16 \mathrm{mg} \mathrm{l}^{-1}\right)$ and trimethoprim/ sulfamethoxazole $\left(\mathrm{MIC}=16 / 304 \mathrm{mg} \mathrm{l}^{-1}\right)$ and susceptible to amoxicillin (MIC $\leqslant 0.016 \mathrm{mg} \mathrm{l}^{-1}$ ), amoxicillin/clavulanic acid (MIC $\leqslant 0.016 \mathrm{mg} \mathrm{l}^{-1}$ ), cephalothin (MIC $\leqslant 0.016 \mathrm{mg} \mathrm{l}^{-1}$ ), cefotaxime $\left(\mathrm{MIC}=0.032 \mathrm{mg} \mathrm{l}^{-1}\right)$, imipenem $\left(\mathrm{MIC}=0.004 \mathrm{mg} \mathrm{l}^{-1}\right)$, erythromycin (MIC $\leqslant 0.016 \mathrm{mg} \mathrm{l}^{-1}$ ), clindamycin (MIC $\leqslant 0.016 \mathrm{mg} \mathrm{l}^{-1}$ ), rifampicin (MIC $\left.\leqslant 0.002 \mathrm{mg} \mathrm{l}^{-1}\right)$, teicoplanin $\left(\mathrm{MIC}=0.5 \mathrm{mg} \mathrm{l}^{-1}\right)$, vancomycin $\left(\mathrm{MIC}=0.25 \mathrm{mg} \mathrm{l}^{-1}\right)$, linezolid $\left(\mathrm{MIC}=0.5 \mathrm{mg} \mathrm{l}^{-1}\right)$ and levofloxacin (MIC $\left.\leqslant 0.016 \mathrm{mg} \mathrm{l}^{-1}\right)$. On the basis of these results, the treatment was changed and a combination of rifampicin plus ofloxacin was administered for 12 weeks. After this prolonged antibiotic therapy, replacement of the prosthesis was successfully performed, with no new infection to date.

Arcanobacterium bernardiae is a nonspore-forming, facultatively anaerobic, Gram-positive rod, with coccobacilli predominating. In 1987, the Centers for Disease Control and Prevention (CDC) described 11 strains of an organism designated coryneform group 2 (Na'was et al., 1987). In 1995, Funke et al. (1995) proposed the name Actinomyces bernardiae sp. nov. for the CDC coryneform group 2 bacteria, based on a comparative $16 \mathrm{~S}$ rRNA sequence analysis. In a more recent taxonomic study, the genus Actinomyces was divided into different genera, with Actinomyces bernardiae and Actinomyces pyogenes assigned to the genus Arcanobacterium as Arcanobacterium bernardiae comb. nov. and Arcanobacterium pyogenes comb. nov., respectively (Ramos et al., 1997). The role of Arcanobacterium bernardiae in human infections has not been clearly established and is limited to a few reports. The bacterium was first described in 1995 by Funke and others, who identified the strain from blood culture and abscesses (Funke et al., 1995). Two cases of severe urinary tract infection and one case of septic arthritis have also been reported. The common trait between these reported cases was the acute infection: severe urinary tract infection complicated by septicaemia (Ieven et al., 1996), urinary tract infection in a patient with a urinary tract diversion (Lepargneur et al., 1998) and septic arthritis (Adderson et al., 1998). Moreover, in the arthritis case, the patient was immunocompromised because of systemic lupus erythematosus treated with corticosteroids and cyclophosphamide (Adderson et al., 1998). Actinomyces pyogenes (Lynch et al., 1998) and Arcanobacterium haemolyticum (Goyal et al., 2005) have been described in arthritis with an acute presentation due to a virulence factor such as $\beta$-haemolysin. This case illustrates the ability of a new species to cause a prosthetic joint infection in an immunocompetent patient. The initial source of Arcanobacterium bernardiae in this case report was unknown, but the organism may be part of the normal skin flora.

In conclusion, this case illustrates a rare occurrence of Arcanobacterium bernardiae 
associated with prosthetic joint infection. Physicians and microbiologists should pay particular attention to Arcanobacterium bernardiae causing opportunistic bone infections to better understand its action as a human pathogen.

\section{Caroline Loïez, ${ }^{1}$ Fabienne Tavani, ${ }^{1}$ Frédéric Wallet, ${ }^{1}$ Bernadette Flahaut, ${ }^{1}$ Eric Senneville, ${ }^{2}$ Julien Girard ${ }^{3}$ and René J. Courcol ${ }^{1}$}

${ }^{1}$ Pôle de Microbiologie, Centre Hospitalier Régional Universitaire, Lille, France

${ }^{2}$ Service des Maladies Infectieuses, 135 rue du Président Coty, Tourcoing, France ${ }^{3}$ Service d'Orthopédie, Centre Hospitalier Régional Universitaire, Lille, France

Correspondence: Caroline Loïez (c-loiez@chru-lille.fr)
Adderson, E. E., Croft, A., Leonard, R. \& Carroll, K. (1998). Septic arthritis due to Arcanobacterium bernardiae in an immunocompromised patient. Clin Infect Dis 27, 211-212.

Atkins, B. L., Athanasou, N., Deeks, J. J., Crook, D. W., Simpson, H., Peto, T. E., McLardy-Smith, P. \& Berendt, A. R. (1998). Prospective evaluation of criteria for microbiological diagnosis of prosthetic-joint infection at revision arthroplasty. The OSIRIS Collaborative Study Group. J Clin Microbiol 36, 2932-2939.

Funke, G., Ramos, C. P., FernandezGarayzabal, J. F., Weiss, N. \& Collins, M. D. (1995). Description of human-derived Centers for Disease Control coryneform group 2 bacteria as Actinomyces bernardiae sp. nov. Int J Syst Bacteriol 45, 57-60.

Goyal, R., Singh, N. P. \& Mathur, M. (2005). Septic arthritis due to Arcanobacterium haemolyticum. Indian J Med Microbiol 23, 63-65.

leven, M., Verhoeven, J., Gentens, P. \&

Goosens, H. (1996). Severe infection due to
Actinomyces bernardiae: case report. Clin Infect Dis 22, 157-158.

Lepargneur, J. P., Heller, R., Soulié, R. \& Riegel, P. (1998). Urinary tract infection due to Arcanobacterium bernardiae in a patient with a urinary tract diversion. Eur J Clin Microbiol Infect Dis 17, 399-401.

Lynch, M., O'Leary, J., Murnaghan, D. \& Cryan, B. (1998). Actinomyces pyogenes septic arthritis in a diabetic farmer. $J$ Infect 37, 71-73.

Na'was, T. E., Hollis, D. G., Moss, C. W. \& Weaver, R. E. (1987). Comparison of biochemical, morphologic, and chemical characteristics of Centers for Disease Control fermentative coryneform groups 1, 2, and A-4. J Clin Microbiol 25, 1354-1358.

Ramos, C. P., Foster, G. \& Collins, M. D. (1997). Phylogenetic analysis of the genus Actinomyces based on 16S rRNA gene sequences: description of Arcanobacterium phoacae sp. nov.,

Arcanobacterium bernardiae comb. nov., and Arcanobacterium pyogenes comb. nov. Int J Syst Bacteriol 47, 46-53. 